\title{
miRNAs expression signature potentially associated with lymphatic dissemination in locally advanced prostate cancer
}

Elena A. Pudova ${ }^{1 *}$, George S. Krasnov ${ }^{1}$, Krill M. Nyushko², Anastasiya A. Kobelyatskaya', Maria V. Savvateeva', Andrey A. Poloznikov², Daniyar R. Dolotkazin², Kseniya M. Klimina³, Zulfiya G. Guvatova', Sergey A. Simanovsky ${ }^{4}$, Nataliya S. Gladysh ${ }^{5}$, Artemy T. Tokarev ${ }^{5}$, Nataliya V. Melnikova', Alexey A. Dmitriev' ${ }^{1}$, Boris Y. Alekseev², Andrey D. Kaprin ${ }^{2}$, Marina V. Kiseleva ${ }^{2}$, Anastasiya V. Snezhkina ${ }^{1}$ and Anna V. Kudryavtseva ${ }^{1}$

From 11th International Young Scientists School "Systems Biology and Bioinformatics" - SBB-2019

Novosibirsk, Russia. 24-28 June 2019

\section{Abstract}

Background: Prostate cancer is one of the most common and socially significant cancers among men. The aim of our study was to reveal changes in miRNA expression profiles associated with lymphatic dissemination in prostate cancer and to identify the most prominent miRNAs as potential prognostic markers for future studies.

Methods: High-throughput miRNA sequencing was performed for 44 prostate cancer specimens taken from Russian patients, with and without lymphatic dissemination (N1 - 20 samples; N0 - 24 samples).

Results: We found at least 18 microRNAs with differential expression between N0 and N1 sample groups: miR-1825p, miR-183-5p, miR-96-5p, miR-25-3p, miR-93-5p, miR-7-5p, miR-615-3p, miR-10b, miR-1248 (N1-miRs; elevated expression in N1 cohort; $p<0.05)$; miR-1271-5p, miR-184, miR-222-3p, miR-221-5p, miR-221-3p, miR-455-3p, miR-143-5p, miR-181c-3p and miR-455-5p (N0-miRs; elevated expression in N0; $p<0.05$ ). The expression levels of N1-miRs were highly correlated between each other (the same is applied for NO-miRs) and the expression levels of NO-miRs and N1-miRs were anti-correlated. The tumor samples can be divided into two groups depending on the expression ratio between N0-miRs and N1-miRs.

Conclusions: We found the miRNA expression signature associated with lymphatic dissemination, in particular on the Russian patient cohort. Many of these miRNAs are well-known players in either oncogenic transformation or tumor suppression. Further experimental studies with extended sampling are required to validate these results.

Keywords: Prostate cancer, microRNA, Lymphatic dissemination, miRNA-Seq, Prognostic markers

\footnotetext{
* Correspondence: rhizamoeba@mail.ru

'Engelhardt Institute of Molecular Biology, Russian Academy of Sciences, Moscow, Russia

Full list of author information is available at the end of the article
}

(c) The Author(s). 2020 Open Access This article is licensed under a Creative Commons Attribution 4.0 International License, which permits use, sharing, adaptation, distribution and reproduction in any medium or format, as long as you give appropriate credit to the original author(s) and the source, provide a link to the Creative Commons licence, and indicate if changes were made. The images or other third party material in this article are included in the article's Creative Commons licence, unless indicated otherwise in a credit line to the material. If material is not included in the article's Creative Commons licence and your intended use is not permitted by statutory regulation or exceeds the permitted use, you will need to obtain permission directly from the copyright holder. To view a copy of this licence, visit http://creativecommons.org/licenses/by/4.0/ The Creative Commons Public Domain Dedication waiver (http://creativecommons.org/publicdomain/zero/1.0/) applies to the data made available in this article, unless otherwise stated in a credit line to the data. 


\section{Background}

Prostate cancer (PC) is the second most common cause of death from cancer among men worldwide [1]. The issue of making an informed decision on PC treatment options after radical prostatectomy (with expanded pelvic lymphadenectomy) remains open. This choice is usually based on the stratification of patients into risk groups depending on several parameters: tumor stage, Gleason index, PSA level, and regional metastasis. Nevertheless, these clinical indicators are not enough, and selecting for a patient group with high potential for tumor progression and further development of aggressive phenotype is one of the most important unsolved tasks of clinical oncology [2, 3]. Therefore, additional reliable markers are needed to guide decisions about treatment type [4].

One promising PC-specific prognostic marker is expression of the fusion transcript TMPRSS2-ERG. The chimeric TMPRSS2-ERG gene is the fusion of the androgen-regulated TMPRSS2 gene with ERG, the most representative member of the oncogenic ETS transcription factor family. It has been demonstrated that TMPR SS2-ERG is found in $40 \%$ of cases of prostate adenocarcinoma [5]. Expression level of TMPRSS2-ERG in the urine negatively correlates with the degree of tumor differentiation (according to Gleason score), and this profile can be used for risk stratification of PC patients [6].

Currently, several commercially available kits allow risk assessment of both tumor progression and aggressive tumor phenotype development (e.g. Oncotype DX Prostate Cancer Assay, Prolaris Score). These commercial kits attempt to predict prognosis after radical prostatectomy; however, none of the available prognostic systems predicts lymphatic dissemination [7].

According to numerous studies, the search for biomarkers is focused on microRNAs (miRNAs) [8, 9]. miRNAs are involved in various cellular pathways, such as proliferation and differentiation, by affecting the expression of their target genes [10, 11].

The miRNA expression profiles of normal and tumor tissues are noticeably different, which can be used to discriminate these tissues [12]. Notably, miRNA profiling seems to have better accuracy in differentiating tumor from normal tissue compared to mRNA profiling [13]. miRNA expression profiles also frequently correspond to clinical and pathological parameters, and thus can predict the patient's response to therapy $[14,15]$. This emphasizes the potential of miRNAs as prognostic markers.

In this study, we performed miRNA-Seq of tumor tissues from Russian patients diagnosed with locally advanced PC (LAPC). Our goal was to identify miRNA expression signatures associated with lymphatic dissemination and to clarify the role of these miRNAs in the development of cell metastatic potential.

\section{Methods}

\section{Tumor tissue samples}

PC tissues samples were obtained from patients who underwent surgical intervention in the P.A. Hertzen Moscow Oncology Research Center (branch of the National Medical Research Radiological Center, Ministry of Health of the Russian Federation) in 2015-2016. All material was collected and characterized by the organization's Pathology Department according to the WHO Classification of Tumors of the Urinary System and Male Genital Organs [16]. Each sample contained a minimum of $70 \%$ tumor cells. Tissue samples were immediately frozen and stored in liquid nitrogen following surgical resection.

In the current study, we used 44 LAPC (adenocarcinoma) samples with negative $(n=24)$ and positive lymph nodes $(n=20)$ obtained from patients who underwent surgical treatment and did not receive neoadjuvant therapy. Samples have the following characteristics: pT3a and $\mathrm{pT} 3 \mathrm{~b}$ categories, negative resection margin, any PSA value, and any Gleason score (Table 1). We did not include normal prostate tissues in the current study.

The study was approved by The Ethics committee of P.A. Hertzen Moscow Oncology Research Center, Ministry of Health of the Russian Federation. The study was done in accordance with the principles outlined in the Declaration of Helsinki (1964). All patients provided written informed consent.

\section{RNA isolation, library preparation, and next generation sequencing (NGS)}

Total RNA was isolated from 44 tumor tissue samples using a MagNA Pure Compact RNA Isolation Kit (Roche, Switzerland). RNA concentration was determined using a Qubit 2.0 Fluorometer (Thermo Fisher Scientific, USA). The RNA integrity number (RIN) was evaluated using an Agilent 2100 Bioanalyzer (Agilent Technologies, USA). RIN for all samples studied was no less than 7.0, on a scale of 1-10.

Libraries were prepared using an NEBNext ${ }^{\circ}$ Small RNA Library Prep Set for Illumina (New England Biolabs, USA) according to the manufacturer's protocol. Libraries were validated prior to sequencing using quantitative PCR (qPCR). Sequencing was performed on a NextSeq500

Table 1 Clinicopathological characteristics of Russian patients

\begin{tabular}{lll}
\hline & Patients N0 & Patients N1 \\
\hline Age (mean) & $51-73(64)$ & $57-73(64)$ \\
PSA (ng/ml) & $4-27,6$ & $7,4-18,41$ \\
Pathological stage $(\mathrm{T})$ & $\mathrm{T} 3 \mathrm{a} / 3 \mathrm{~b}$ & $\mathrm{~T} 3 \mathrm{a} / 3 \mathrm{~b}$ \\
Pathological Gleason & $6-9$ & $7-9$ \\
Surgical margin & negative & negative \\
Neoadjuvant therapy & no & no \\
\hline
\end{tabular}


System (Illumina) at the EIMB RAS "Genome" Center [http://www.eimb.ru/rus/ckp/ccu_genome_c.php].

\section{miRNA-Seq data analysis}

To process miRNA-Seq data, we used the miRge 2.0 pipeline [17]. Besides de novo miRNA prediction, this pipeline provides annotation of miRNA-seq data against a known miRNA database. In brief, miRge 2.0 trims adapter sequences with the Cutadapt package, maps reads to miRBase v22 [18]) as well as tRNA, snoRNA, ncRNA and mRNA datasets, and calculates miRNA abundance. Next, we analyzed read counts data using the edgeR package [19] and compared N0 and N1 groups. We used TMM normalization and then calculated CPMs considering normalization factors derived with TMM method (e.g. CPM $=$ read_counts_per_miRNA / total_read_count * 1.000.000 / TMM_norm_factor). Additionally, we compared several normalization methods: RLE, TMM, upper quartile and 'total read count'. Next, we applied quasilikelihood F-test (QLF) and the Mann-Whitney (MW) nonparametric test. Benjamini-Hochberg adjustment was applied to calculate the false discovery rate (FDR).

miRNA expression level differences were treated as statistically significant if they underwent a 1.5-fold change or greater and for both QLF and MW tests had FDR $<0.05$. Additionally, for each miRNA, we calculated portions of samples with high and low relative expression (lower than average/1.5 or higher than average $\left.{ }^{*} 1.5\right)$ and compared these frequencies between $\mathrm{N} 0$ and $\mathrm{N} 1$ cohorts.

Next, we tried to identify the pathways most affected by differentially expressed (DE) miRNAs. For this purpose, we used the mirPath 3.0 (DIANA tools) web service [20] and TarBase 7.0 data [21]. Visualization of the number of miRNAs targeting members of KEGG pathways was performed with the pathview package (R, Bioconductor) [22]. Additionally, we performed association network reconstruction and GO, KEGG, Reactome, SMART, InterPro, and Pfam enrichment using the STRI NG web service [23].

\section{Results and discussion}

\section{MicroRNAs associated with lymphatic dissemination}

A total of 301 miRNAs passed the read-counts-per-million (CPM) thresholds for further analysis (Additional file 1). Among these, 18 miRNAs passed the statistical significance threshold $p<0.05$ (both Mann-Whitney (MW) and quasilikelihood F-test (QLF) tests), and 1.5-fold expression level changes between N0 and N1 groups. Among these 18 microRNAs, there are 9 ones that are overexpressed in N1 tumors, compared to N0 (further we will denote these microRNAs as "N1-miRs"): miR-182-5p, miR-183-5p, miR96-5p, miR-25-3p, miR-93-5p, miR-7-5p, miR-615-3p, miR$10 \mathrm{~b}$ and $\mathrm{miR}-1248$; and $9 \mathrm{miRs}$ that are underexpressed in N1 tumors, compared to N0 (further - N0-miRs): miR- 1271-5p, miR-184, miR-222-3p, miR-221-5p, miR-221-3p, miR-455-3p, miR-143-5p, miR-181c-3p and miR-455-5p.

Notably, all the nine N1-miRs are highly correlated to each other, with except for miR-10b-5p. The average pairwise Spearman's rank correlation coefficient is $r=$ 0.63 ; for almost all pairs, $p<0.001$ (Additional file 2). Similarly, all nine N0-miRs are also highly selfcorrelated: average $r=0.54$, and for the most of pairs, $p<0.001$. In turn, all N1-miRs are anti-correlated to N0miRs: average $r=-0.55$, and $p<0.001$ for the most of pairs, except for miR-10b-5p. In other words, we can speak about a microRNA expression signature characteristic of tumors with lymphatic dissemination. On the Fig. 1, the difference of average $\log 2 F C$ values between N1-miRs and N0-miRs is designated as $\Delta$ avg. $\log 2 F C$. Hence, we see that the samples are divided into two groups: G0 (with $\Delta a v g . \log 2 F C<0$ ) and G1 (with $\Delta a v g$. $\log 2 F C>0)$. N1 cohort is significantly enriched with $\mathrm{G} 1$ samples, and N0 cohort - with G0 samples $(p=0.03$, Fisher's exact test).

Additionally, we performed comparison of several data normalization methods (TMM, RLE, upper quartile, total read count). These methods gave almost identical results; 'total read count' normalization method mostly diverged from other ones.

It is expected that the degree of cancer cell differentiation should be negatively associated with lymphatic dissemination, and contribute to the increased invasion. In other words, Gleason score, which is negatively associated with cell differentiation degree, should correlate with the presence of lymph node metastases. Indeed, Gleason score strongly correlated with N0-N1 (Spearman's $r=0.45, p=$ 0.002). Moreover, expression levels of several N1-miRs (miR-182-5p, miR-183-5p, miR-615-3p, miR-25-3p) positively correlated with Gleason score $(r=0.32 \ldots 0.45, p<$ 0.05 ), and expression of the most of N0-miRs (miR-184, miR-222-3p, miR-221-3p/5p, miR-143-5p, miR-455-5p) was negatively associated $(r=-0.32 \ldots-0.44, p<0.05)$.

\section{Upregulated microRNAs associated with lymphatic dissemination (N1-miRs)}

According to the results of microRNAs expression profiling of 48 LAPC samples, the following microRNAs upregulated in $\mathrm{N} 1$ (compared to N0) have been identified: miR-182-5p, miR-183-5p, miR-96-5p, miR-25-3p, miR93-5p, miR-7-5p, miR-615-3p, miR-10b and miR-1248 (denoted as N1-miRs).

Three of the identified microRNAs, miR-182-5p, 183-5p and-96-5p, are members of the miR-183-96182 oncogenic cluster. Various studies demonstrate that the miR-183-96-182 cluster plays an important role in oncogenesis, cancer progression, tumor invasion and metastasis. Thus, miR-183 supports tumor invasion and metastasis by targeting target genes such as PDCD4, 


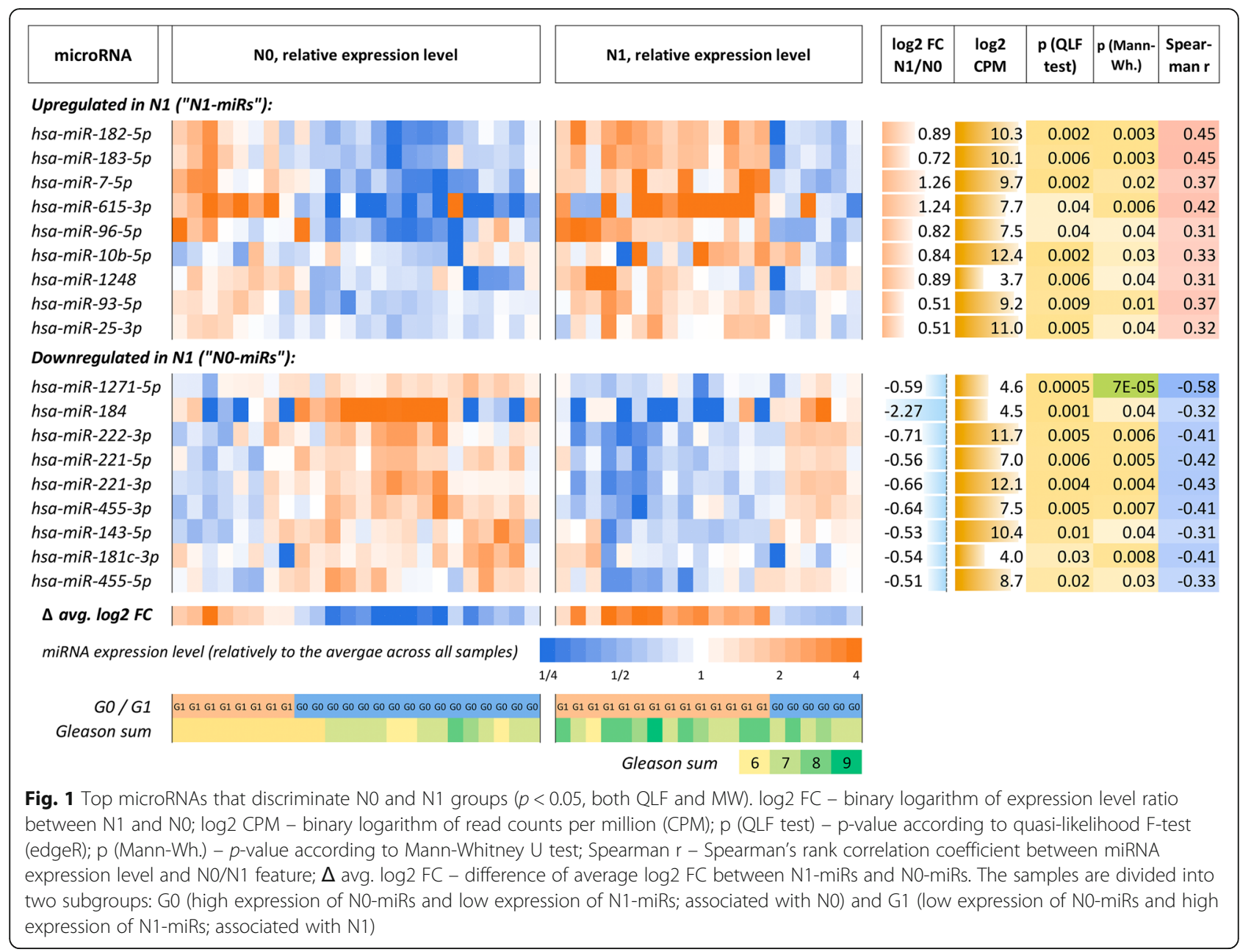

PP2A, EGR1, and PTEN [24-26]. The well-known prostate tumor suppressor PTEN has been shown to be regulated by miR-183-5p and miR-96-5p and promote cell proliferation in breast cancer by directly affecting the tumor suppressor gene FOXO3a and cyclin-dependent kinase inhibitors $\mathrm{p} 27^{\mathrm{Kip} 1}$ and $\mathrm{p} 21^{\mathrm{Cip} 1}$ [27].

All three miRs, (96, 182 and 183) cause downregulation of FOXO1 tumor suppressor, which induce cell cycle arrest and cell death in endometrial cancer [28]. Additionally, FOXO1 has been suggested to act as a repressor of androgen receptor activity, which is the central oncogenic pathway in the development of prostate cancer [29]. There is a report that metastasis of prostate cancer is promoted by stimulation of the TGF- $\beta$ and SMAD genes by inducing miR-96 and activating the mTOR pathway [30]. The TGF- $\beta$ gene also activates miR-182, which can affect the CYLD gene, which can further contribute to the activation of NF- $\mathrm{kB}$, which was demonstrated in the case of glioblastoma, and subsequently lead to angiogenesis and tumor invasion [31]. Increased expression of miR-182-5p was demonstrated in prostate cancer tissues compared with normal tissue, and moreover, the expression level of miR-182-5p allows us to distinguish tumor from non-tumor tissue with 100\% specificity [32-34]. Thus, miR-183-96-182 cluster is prospective prostate cancer prognosis biomarker candidate, and further studies on an extended cohort are needed to accurately assess its clinical significance and the limits of applicability.

Two other microRNAs with predominantly increased expression level in N1 samples, miR-25 and miR-93, along with miR-106 are the members of a highly conserved oncogenic miR-106b-25 cluster. It is overexpressed in many types of cancer, including gastric, prostate, and pancreatic neuroendocrine tumors, neuroblastoma and multiple myeloma [35]. The miR-106b-25 clusters, as well as the miR-17-92 oncogenic cluster, are key modulators of transforming growth factor beta (TGF- $\beta$ ) signaling. Inactivation of TGF- $\beta$ tumor pathway is a major step in the development of various human tumors. Modulation of TGF- $\beta$ signaling in tumors thus prevents cell cycle arrest and apoptosis when overexpressed in cancer cells [35]. Previous studies have reported that miR-25-3p is associated with various types 
of tumors, including prostate cancer [36]. MiR-25 has been identified as an important regulator of invasive programs in non-transformed and malignant epithelial tissues of the human prostate gland. It was previously reported that in primary tumors and distant metastases in prostate cancer, increased regulation of miR-25-3p is observed [37, 38]. miR-93-5p likewise has an association with various types of cancer $[39,40]$. Increased expression of exosomal miR-93-5p in plasma is significantly associated with both the risk of esophageal cancer and a poor prognosis for the disease [39]. In prostate cancer, increased expression of miR-93-5p associated with progression has been described [41].

Regarding miR-7-5p, it has been shown that it acts as a tumor suppressor in certain types of human cancers [42-44]. However, the role of miR-7-5p in prostate cancer remains to be explored. Aberrant expression of miR-615-3p has been described in many cancers, including prostate cancer, where increased expression of miR-615-3p has been observed in the most aggressive forms [45-47]. Experiments on cell lines of various types of cancer have shown that overexpression of miR-615-3p supports cell proliferation and migration [45, 46]. Functional studies carried out on PC3M prostate cancer cell lines showed that miR-615-3p promotes the proliferation, apoptosis and migration of PC3M prostate cancer cells in vitro, which indicates that miR-615-3p is a significant oncogenic microRNA in prostate cancer [47].

The presence of miR-10b was detected in various types of malignant neoplasms [48, 49]. It has been shown that increased expression of miR-10b was observed in metastatic melanoma cells and was positively associated with lymph node metastasis, a progressive clinical stage, and poorer survival [48]. A similar association of increased expression of miR-10b with lymph node metastases has been described in gastric cancer [50]. The least miRNA upregulated in N1, miR-1248, is poorly studied, and so far no reports have addressed to its biological function.

\section{Downregulated microRNAs associated with lymphatic dissemination (NO-miRs)}

Among microRNAs with lowered expression level in N1 samples compared to N0, the following ones have passed the statistical significance thresholds: $m i R-1271-5 p, m i R$ 184, miR-222-3p, miR-221-5p, miR-221-3p, miR-455-3p, miR-143-5p, miR-181c-3p and miR-455-5p (denoted as N0-miRs).

Among them, there are several tumor suppressors microRNAs, but the role of the most of them may be dual and depends on a current biological context. MiR1271-5p acts as a tumor suppressor in breast cancer, inhibits cell proliferation by suppressing SPIN1 gene [51]. In the case of hepatocellular carcinoma, a decreased expression of miR-1271-5p is also observed, which may be associated with oncogenic effects [52]. In the case of osteosarcoma, it was demonstrated that miR-1271-5p inhibited cell proliferation and invasion by Wnt signaling [53]. A study in cell cultures reports inhibition of miR1271-5p expression in ovarian cancer cells compared to normal [54].

Reduced expression of miR-184 was also detected in various types of human cancer, including renal cell [55], nasopharyngeal cancer [56], neuroblastoma [57], nonsmall cell lung cancer [58], glioma and breast cancer [59]. MiR-184 has been shown to act as tumor suppressor, and downregulated miR-184 level may be a predictor of poor prognosis in patients with non-small cell lung cancer [58].

Two other microRNAs that are decreased in N1 cohort, MiR-221 and miR-222, represent two partially homologous miRNAs that are encoded in tandem on chromosome X. In prostate cancer cells PC3, they target cell cycle inhibitor $\mathrm{p} 27^{\mathrm{Kip} 1}$ and thus affect PC3 proliferation potential [60]. Normally, these miRs mediate vascular remodeling, a response to vascular injury, by controlling endothelial cells differentiation and inhibiting their proliferation and migration [61, 62]. These miRNAs have been extensively studied in many human malignancies (including prostate cancer), and their act either as tumor suppressors or oncogenes $[60,63-65]$. It was revealed that miR-221 (both $3 p$ and $5 p$ ) are downregulated during prostate cancer progression [66], miR-221-5p acts as tumor suppressor miRNA in prostate cancer cell lines and reduces tumor burden in mouse and zebrafish in vivo models. miR-221 was identified as key regulator of a network of other miRNAs in prostate cancer and has the potential to drastically modulate cell physiology [67]. Thus, the biological role and underlying mechanisms of miR221 and miR-222 in the pathogenesis of androgenindependent prostate cancer are still unclear.

Another microRNA with decreased expression level in N1, miR-455-3p is involved in many pathological processes. In comparison with normal tissues, miR-455-3p has been shown to have reduced expression in various cancer tissues $[68,69]$. It was found that miR-455-3p expression in prostate cancer tissues was significantly reduced compared to normal, demonstrating that miR-455-3p is associated with prostate carcinogenesis. Also, experiments on cell cultures showed that increased expression of miR-455-3p inhibits the growth of prostate cancer cells in vitro and in vivo. These research results show that miR-455-3p plays the role of a tumor suppressor in the prostate cancer progression [70].

MiR-143-5p is downregulated in gastric cancer and gallbladder cancer tissues and that forced miR-143-5p expression suppresses cancer cell malignancy through targeting COX-2 and HIF1- $\alpha$, respectively [71, 72]. In the case of cervical cancer, miR-143-5p has been shown to reduce the expression level of the Cyclin D1 and Bcl-2 protein in vivo and in vitro. miR-143-5p inhibits the 
progression, proliferation, migration and invasion of the cervical cell cycle, and also inhibits apoptosis of cervical cancer cells, suppressing the expression levels of the ELK1, p-ELK1, C-fos, Cyclin D1 and Bcl-2 protein [73].

miR-181c is also involved in various pathological pathways, including the important role in various cancers, such as colorectal cancer, breast cancer, and stomach cancer [74-76]. In a study of osteosarcoma, it was found that a decrease in miR-181c expression level was associated with a poor prognosis and malignant clinical and pathological features. As a result of functional studies, it was shown that activation of miR-181c dramatically inhibited the proliferation, invasion and migration of osteosarcoma cells [77]. It was also revealed that the SMAD7 gene was a direct functional target for miR-181c in osteosarcoma cells and that overexpression of miR181c suppresses the signaling pathway of EMT and TGF- $\beta$ in osteosarcoma cells through regulation of SMAD7 [77]. Significant downregulation of miR-181c was also detected in the case of hepatocellular carcinoma when compared with normal tissues. miR-181c regulated migration, invasion, apoptosis, and proliferation of hepatocellular carcinoma cell lines in vitro and tumor development in vivo [78].

miR-455-5p is involved in many pathological processes, such as cell proliferation, apoptosis, migration, and invasion. miR-455-5p successfully suppresses cell viability and induces cell apoptosis by targeting RAF1 gene in colorectal cancer [79] and miR-455-5p is significantly downregulated in gastric cancer cells and can inhibit the proliferation and invasion of human gastric cancer cells, as well as promote cell apoptosis by affecting $R A B 18$ gene [80]. In addition, low miR-455 expression was associated with multiple tumor nodes and progressive stage metastatic tumor nodes in hepatocellular cancer and could significantly inhibit the migration and invasion [81]. In case of prostate cancer, the miR-455-5p tumor suppressor function has been shown to significantly suppress proliferation and initiate apoptosis of prostate cancer cells. The authors also experimentally determined a functional target for miR-455-5p - CCR5 gene [82].

\section{Pathway enrichment analysis of microRNAs over- and underexpressed in $\mathrm{N} 1$ group}

Using DIANA mirPath v.3 web server and TarBase 7.0 data, we performed pathway enrichment analysis of nine N1-miRs and nine N0-miRs, which have passed statistical significance thresholds. For N1-miRs, we identified 66 enriched KEGG pathways $(p<0.05), 23$ of which have passed $p<10^{-5}$ threshold. Among them, we should mention the following ones: protein processing in endoplasmic reticulum (hsa04141), proteoglycans in cancer (hsa05205), cell cycle (hsa04110), adherens junction (hsa04520), FoxO signaling pathway (hsa04068), p53 signaling pathway (hsa04115), pathways in cancer (hsa05200), prostate cancer (hsa05215).

For N0-miRs, mirPath has found 33 pathways with $p<0.05$, only 5 of which have passed $p<10^{-5}$ threshold. Among these pathways, we noticed: protein processing in endoplasmic reticulum (hsa04141), mRNA surveillance pathway (hsa03015), proteoglycans in cancer (hsa05205), adherens junction (hsa04520), ECMreceptor interaction (hsa04512), Hippo signaling pathway (hsa04390), transcriptional misregulation in cancer (hsa05202), cell cycle (hsa04110). Surprisingly, several pathways take first places among the enriched pathways for both N1- and N0-miRs: protein processing in endoplasmic reticulum pathway, adherens junctions, proteoglycans in cancer, and cell cycle.

Figure 2 demonstrates the number of targets of upand down- regulated microRNAs among genes involved in cell cycle regulation, according to TarBase 7.0 data. Among them, N1-miRs (Fig. 2a) have more putative targets than N0-miRs (Fig. 2b), but the spectra of these targets are quite different. Among putative targets of N1-miRs (Fig. 2a), we noticed SMAD2, SMAD3, SMAD4, p53, Rb, p27 ${ }^{\text {Kip1 }}$, $p 21^{\text {Cip1 }}$, GADD45, Wee1, GSK3- $\beta$ which have tumor suppression activity and potential to inhibit cell cycle progression. Although some of these genes are also targeted by N0-miRs (for example p27 ${ }^{\mathrm{Kip} 1}$ ), the overall number of mRNA targets with tumor suppression potential is greater for N1-miRs.

In general, we can say that N1-miRs demonstrate better coherence in the lists of mRNA targets rather than N0-miRs. The main reason is that the list of N1-miRs include a cluster of three microRNAs (miR-96/182/183). For example, there are 157 genes that are targeted by simultaneously 5 or more N1-miRs and only 11 genes are found as targets of simultaneously 5 or more N0miRs (TarBase 7.0 data).

Besides this, we noticed a significant number of prooncogenes, which are targets of N0-miRs, whereby they may be suppressed in non-metastatic tumors:

- At least four N0-miRs (miR-181c-3p, 221-5p, 222-3p, 455-3p) target $c-M y c$, well known pro-tumorigenic transcription factor. $\mathrm{c}-\mathrm{Myc}$ contributes to disease initiation and progression by stimulating an embryonic stem cell-like signature characterized by an enrichment of genes involved in ribosome biogenesis and by repressing differentiation [83]. In turn, the loss of cell differentiation is known to be associated with increases metastatic capability and disease recurrence [84].

- Several N0-miRs (both miR-221-3p/5p, both miR455-3p/5p) target THBS1 (thrombospondin 1) encoding for an adhesive glycoprotein that mediates cell-to-cell and cell-to-matrix interactions. It has negative impact on angiogenesis. This protein can 


\section{A. microRNAs overexpressed in N1 tumors (comp. to NO)}

the number of regulatory microRNAs

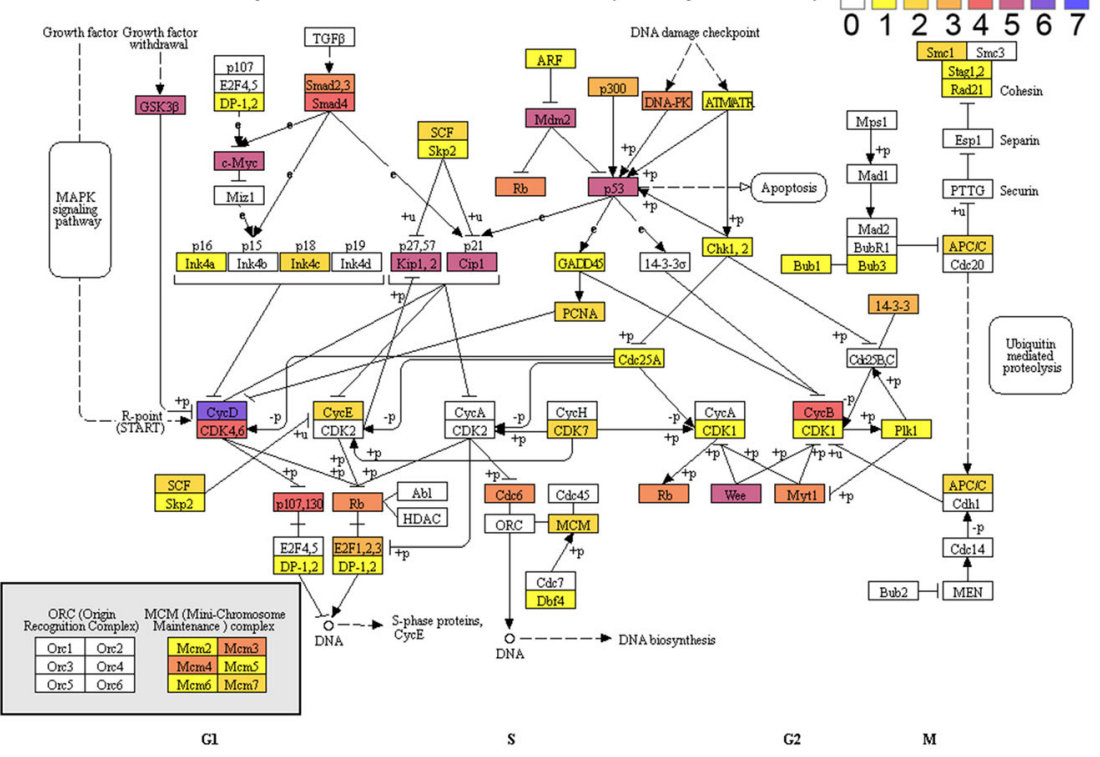

B. microRNAs underexpressed in N1 tumors (comp. to NO)

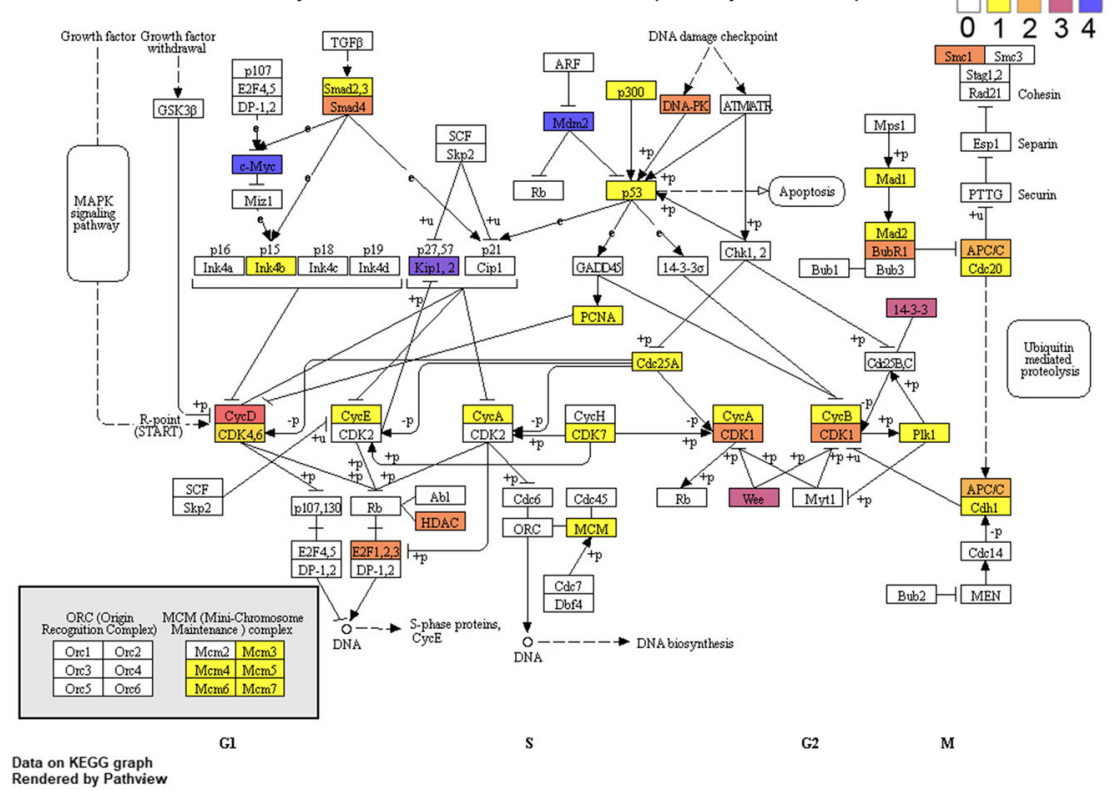

Fig. 2 Targets of overexpressed (a) and downregulated (b) microRNAs (N1 versus N0) among genes participating cell cycle progression and regulation (KEGG pathway hsa04110 - cell cycle). Each rectangle corresponds to a single KEGG node, which can be represented either by one or several genes. The numbers of microRNAs between the genes comprising a single KEGG node are averaged (e.g. value for "Smad2,3" node is averaged between two genes, SMAD2 and SMAD3)

bind to fibrinogen, fibronectin, laminin, type $\mathrm{V}$ collagen and integrins alpha-V/beta- 1 and affects signal transduction. THBS1 is multifaceted player in tumor progression; it affects tumor cell adhesion, invasion, migration, proliferation, apoptosis and tumor immunity [85]. The precise role of THBS1 in tumor invasion and migration remains controversial, with compelling evidence suggesting both stimulatory and inhibitory roles [85].

- At least four microRNAs (miR-181c-3p, 221-3p, 222-3p, 1271-5p) target MDM2, an important negative regulator of the p53 tumor suppressor. MDM2 protein functions both as an E3 ubiquitin ligase that recognizes the $\mathrm{N}$-terminal trans-activation domain 
(TAD) of the p53 tumor suppressor and as an inhibitor of p53 transcriptional activation. This is well known pro-oncogenic protein which represents a target for anti-tumor therapy (in p53-dependent manner), including prostate cancer [86-88].

- Several microRNAs also target FRS2 (fibroblast growth factor receptor substrate 2), which participate signal transduction from receptor tyrosine kinases (RTKs) to multiple downstream signaling pathways, most notably the MAPK/ERK, $\mathrm{PI} 3 \mathrm{~K} / \mathrm{AKT} / \mathrm{mTOR}$ and PLCy. It is overexpressed and amplified in several cancer types, including prostate cancer $[89,90]$.

Beyond them, we can notice several cancer-associated genes, which are putative targets of N0-miRs: CCND1,
$C D K 4 / 6$, laminin, syndecan, beta-catenin, CREB, $C C N D 2, M L L$. On other hand, we also see that N1-miRs target several gene with pro-oncogenic potential (member of Ras and ERK families, HIF1A and other ones).

Next, we selected 157 genes, which are targeted by at least 5 of our 9 N1-miRs, according to TarBase 7.0 data. For these genes, we performed network analysis and pathway enrichment using the STRING database (Fig. 3). The network that emerged is highly enriched with protein-protein interactions $\left(p<10^{-16}\right)$. This indicates that the genes and proteins we examined are biologically connected. As can be seen from the Fig. 3, network core consists of participants of cell cycle regulation, checkpoints, including TP53, CCND1, CCND2, CDKN1A, BTG2, TAOK1, MYC, CNOT6 and other genes (marked with blue or red).

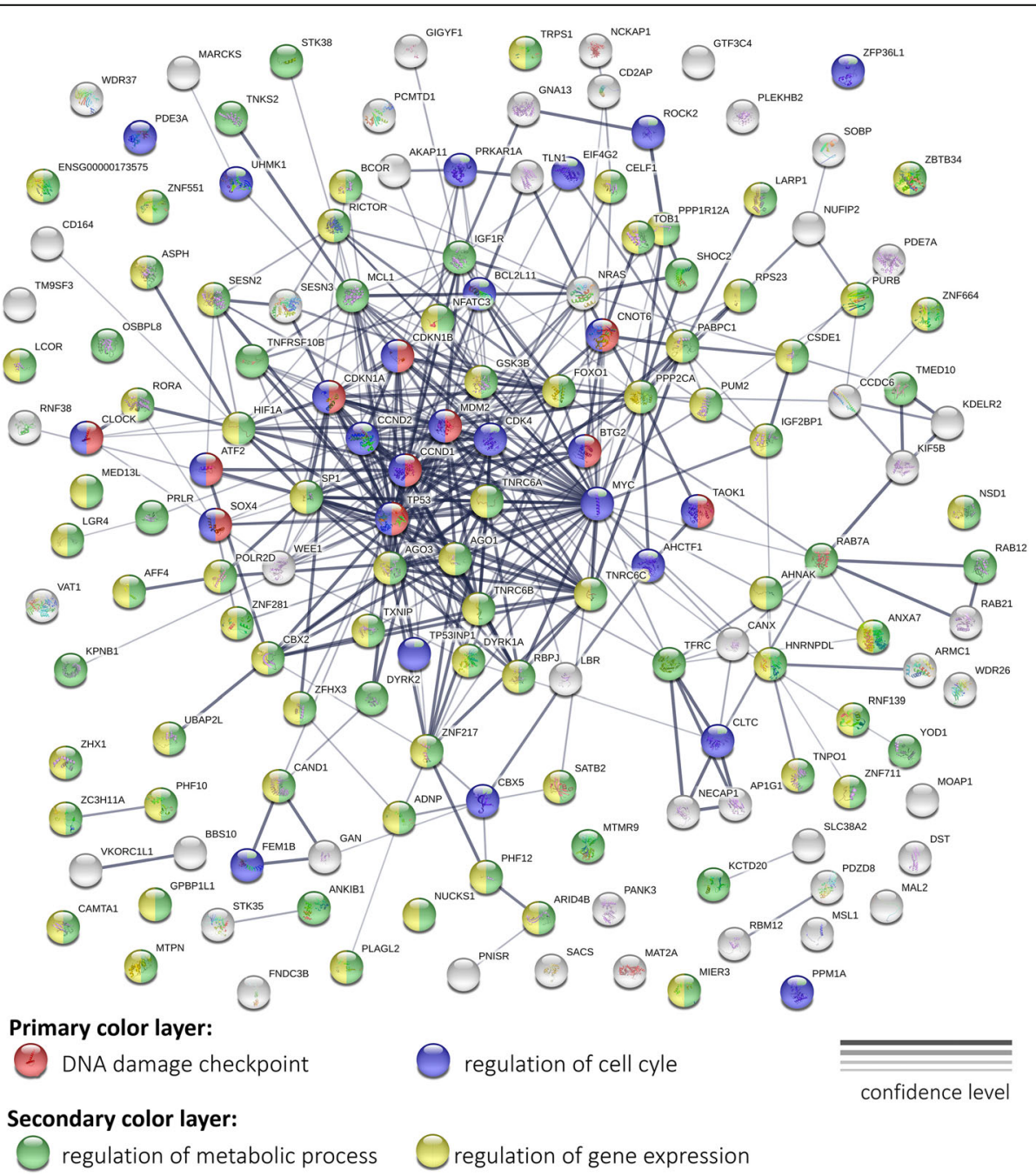

Fig. 3 The interaction network of 157 genes that are targets of at least 5 microRNAs overexpressed in N1 tumors (N1-miRs). Foreground color layer indicates whether a gene participate regulation of the cell cycle (blue) and/or DNA damage checkpoints system (red). If a gene does not belong to these categories, but is involved in the regulation of cellular metabolism or the gene expression, then it is marked with yellow or green (background color layer) 


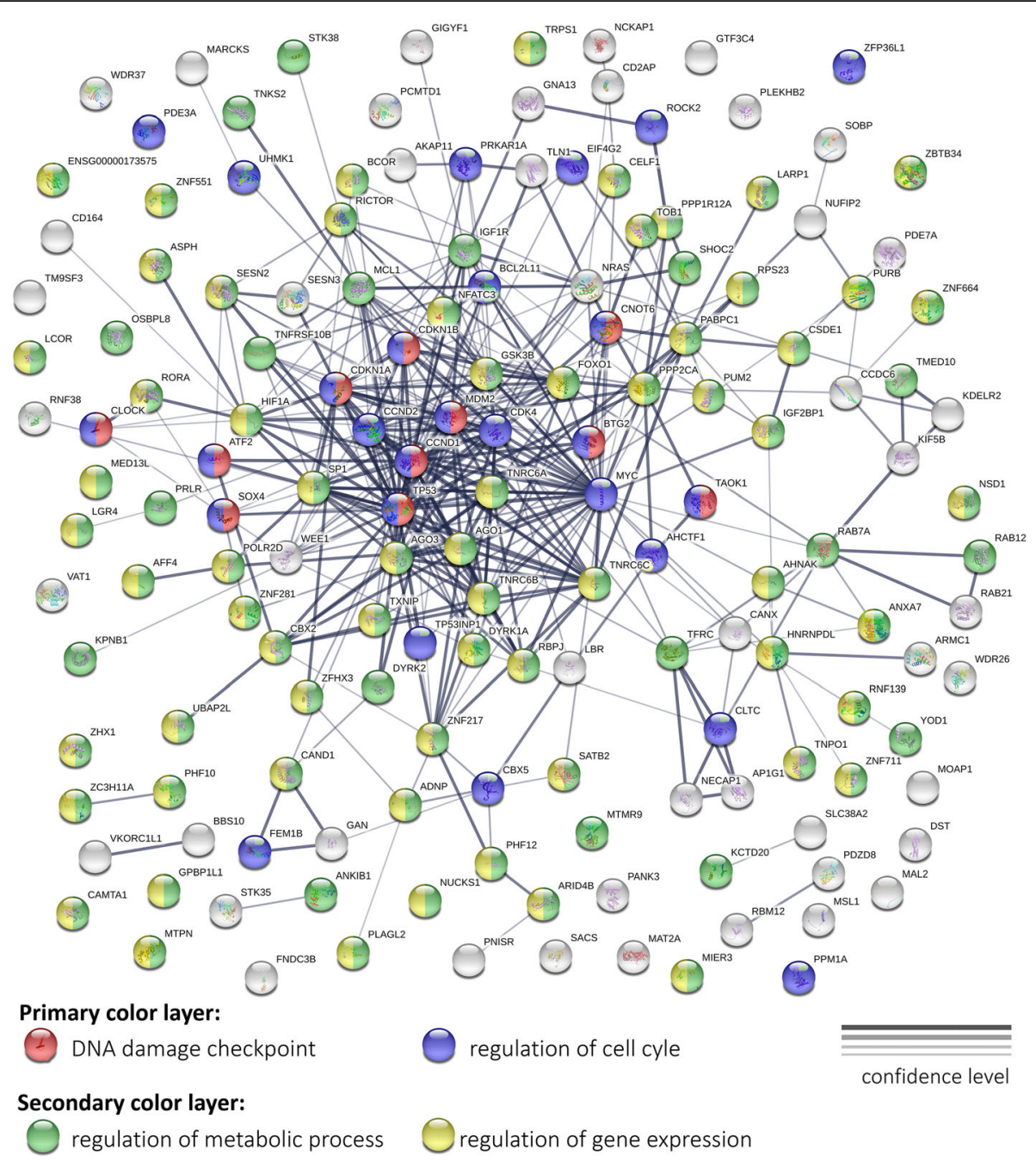

Fig. 4 The interaction network of 139 genes that are targets of at least 3 microRNAs underexpressed in N0 tumors (N0-miRs). Foreground color layer indicates whether a gene participate negative regulation of apoptotic process (orange) and/or negative regulation of cell differentiation (blue). If a gene does not belong to these categories, but is involved in the regulation of cellular metabolism or the gene expression, then it is marked with yellow or green (background color layer)

In addition, this list of 157 genes is highly enriched with participants of regulation of metabolic processes (GO:0019222), regulation of gene expression (GO: 0010468), regulation of translation (GO:0006417), negative regulation of cell cycle (GO:0045786), mitotic DNA damage checkpoint (GO:0044773), gene silencing by miRNA (GO:0035195) and other terms (Additional file 3). Besides these GO terms, we observed enrichment with participants of Reactome pathways: Oncogene Induced Senescence (HSA-2559585), Transcriptional Regulation by TP53 (HSA-3700989); KEGG pathways: p53 signaling pathway (hsa04115), MicroRNAs in cancer (hsa05206), Cellular senescence (hsa04218), Prostate cancer (hsa05215). As can be seen, among them, most of the pathways in one way or another are associated with tumor suppression, as well as regulation of gene expression due to miRNAs. This is mainly about genes: CCND1, CCND2, CDK4, CDKN1A, SESN2, SESN3, TNFRSF10B, TNRC6A/B/C, BTG2, TP53, PPP2CA, most of them are tumor suppressors [91-94]. Of course, the list of enriched pathways was not limited to those associated with tumor suppression. Among them were the single pathways associated with tumor progression, for example, PI3K-Akt signaling pathway (Additional file 3).

Among protein domains encoded by 157 genes, we observed enrichment in Argonaute hook (TNRC6A, TNRC6B, TNRC6C), protein kinase domains (CDK4, DYRK1A, DYRK2, GSK3B, IGF1R, ROCK2, STK35, STK38, TAOK1, UHMK1, WEE1), RNA recognition motifs (CELF1, HNRNPDL, IGF2BP1, PABPC1, RBM12, TNRC6C, UHMK1), Argonaute domains (AGO1, $A G O 3)$. For the complete results of enrichment analysis, 
see the Supplementary Table S3. Thus, among potential targets of miRNAs, we see not only tumor suppressors, but also directly genes involved in miRNA-mediated suppression of expression, e.g. Argonaute proteins $A G O 1 / 3$ and Argonaute-navigating proteins TNRC6 $A / B / C$.

Next, we performed the same procedure for 139 genes, the targets of at least 3 out of 9 N0-miRs (Fig. 4). The network is also highly enriched with protein-protein interactions $(p=$ $7.5 \cdot 10^{-14}$ ). Here, pro-oncogenic c-Myc is located in the center of the network and is connects to almost 30 peripheral nodes. Gene Ontology, KEGG and Reactome enrichment analyses demonstrated that the list of 139 genes contains elevated number of participants gene expression regulation (GO:0010468), regulation of metabolic process (GO: 0019222), developmental process (GO:0032502), gene silencing by miRNA (GO:0035195), regulation of cell differentiation (GO:0045596; predominantly negative, GO:0045596), regulation of apoptotic process (GO:0042981; predominantly negative, GO:0043066); microRNAs in cancer KEGG pathway (hsa05206), PI3K-Akt signaling pathway (hsa04151); Transcriptional Regulation by TP53 (HSA-3700989). For the complete list of enriched pathways see the Additional file 4.

\section{Conclusions}

We revealed at least 18 microRNAs with statistically significant difference in the expression profiles between NO and N1 tumors: 9 N1-miRs, which are upregulated in lymph node-positive samples, and $9 \mathrm{N0}$-miRs, which are dowregulated in lymph node-positive samples. The expression levels of these microRNAs are significantly (anti)correlated to each other.

In turn, the samples examined can be divided into two groups (G1 and G0) according to the difference of expression levels between N0-miRs and N1-miRs. Lymph node positive (N1) group is significantly enriched with G1 tumors.

Many N1-miRs serve as putative negative regulators of genes participating cell cycle arrest and inhibiting tumor growth, including several tumor suppressors CCND1, CCND2, CDK4, CDKN1A, SESN2, SESN3, TNFRSF1OB, TNRC6A/B/C, BTG2, TP53, PPP2CA. In turn, many N0miRs can serve as putative suppressors of genes participating cell cycle progression, negative regulation of cell differentiation.

\section{Supplementary information}

Supplementary information accompanies this paper at https://doi.org/10. 1186/s12920-020-00788-9.

Additional file $\mathbf{1}$ Table S1. Total of 301 miRNAs passed the readcounts-per-million (CPM) thresholds.

Additional file $\mathbf{2}$ Table S2. Spearman's correlation analysis of microRNAs associated with lymphatic dissemination. (
Additional file 3 Table S3. The enriched pathways list of 157 genes that are targets of at least 5 microRNAs overexpressed in N1 tumors.

Additional file $\mathbf{4}$ Table S4. The enriched pathways list of 139 genes that are targets of at least 3 out of 9 microRNAs overexpressed in N0 tumors.

\section{Abbreviations}

PC: Prostate cancer; LAPC: Locally advanced prostate cancer; CPM: Read counts per million; LogCPM: Binary logarithm of reads counts per million; QLF test: Quasi-likelihood F-test; Mann-Wh:: Mann-Whitney U-test; LogFC: Binary logarithm of expression level fold change;

Spearman: Spearman's rank correlation coefficient

\section{Acknowledgments}

The authors thank the National Medical Research Radiological Center for providing the samples and their morphological characterization. This work was performed using the equipment of the EIMB RAS "Genome" center (http://www.eimb.ru/rus/ckp/ccu_genome_c.php).

\section{About this supplement}

This article has been published as part of BMC Medical Genomics Volume 13 Supplement 8, 2020: Selected Topics in "Systems Biology and Bioinformatics" - 2019: medical genomics. The full contents of the supplement are available online at https://bmcmedgenomics.biomedcentral.com/articles/supplements/ volume-13-supplement-8.

\section{Authors' contributions}

EAP, GSK, AVK, KMN, ADK, BYA, ADK and MVK conceived and designed the work; EAP, AVS, NVM, MVS, AAP, DRD, KMK, NSG, ATT and ZGG performed the experiments; GSK, EAP, AAK, SAS, NVM and AAD analyzed the data; EAP, GSK and AVK wrote the manuscript. All authors read and approved the final manuscript.

\section{Funding}

This work and publication costs were financially supported by the Russian Science Foundation, grant 18-75-10127. The funding body played no role in the design of the study and collection, analysis, and interpretation of data and in writing the manuscript.

\section{Availability of data and materials}

All data generated or analyzed in this study are included in the published article. microRNA transcriptome sequence data are available at the NCBI Sequence Read Archive (BioProject PRJNA562642).

\section{Ethics approval and consent to participate}

The study was approved by The Ethics committee of P.A. Hertzen Moscow Oncology Research Center, Ministry of Health of the Russian Federation. The study was done in accordance with the principles outlined in the Declaration of Helsinki (1964). All patients gave their informed consent for participation in the study.

Consent for publication

Not applicable.

\section{Competing interests}

The authors declare that they have no competing interests.

\section{Author details}

${ }^{1}$ Engelhardt Institute of Molecular Biology, Russian Academy of Sciences, Moscow, Russia. ${ }^{2}$ National Medical Research Radiological Center, Ministry of Health of the Russian Federation, Moscow, Russia. ${ }^{3}$ Vavilov Institute of General Genetics, Russian Academy of Sciences, Moscow, Russia. ${ }^{4}$ A. N. Severtsov Institute of Ecology and Evolution, Russian Academy of Sciences, Moscow, Russia. ${ }^{5}$ MSAVM\&B - MVA named after K.I. Skryabin, Moscow, Russia. 


\section{Received: 19 July 2020 Accepted: 31 August 2020} Published: 18 September 2020

\section{References}

1. Jemal A, Bray F, Center MM, Ferlay J, Ward E, Forman D. Global cancer statistics. CA Cancer J Clin. 2011;61(2):69-90.

2. Moschini M, Spahn M, Mattei A, Cheville J, Karnes RJ. Incorporation of tissue-based genomic biomarkers into localized prostate cancer clinics. BMC Med. 2016;14:67.

3. Sternberg IA, Vela I, Scardino PT. Molecular profiles of prostate Cancer: to treat or not to treat. Annu Rev Med. 2016;67:119-35.

4. Attard G, Parker C, Eeles RA, Schroder F, Tomlins SA, Tannock I, Drake CG, de Bono JS. Prostate cancer. Lancet. 2016:387(10013):70-82.

5. Tomlins SA, Rhodes DR, Perner S, Dhanasekaran SM, Mehra R, Sun XW, Varambally S, Cao X, Tchinda J, Kuefer R, et al. Recurrent fusion of TMPRSS2 and ETS transcription factor genes in prostate cancer. Science. 2005; 310(5748):644-8

6. Lin DW, Newcomb LF, Brown EC, Brooks JD, Carroll PR, Feng Z, Gleave ME, Lance RS, Sanda MG, Thompson IM, et al. Urinary TMPRSS2:ERG and PCA3 in an active surveillance cohort: results from a baseline analysis in the canary prostate active surveillance study. Clin Cancer Res. 2013;19(9):2442-50.

7. Na R, Wu Y, Ding Q, Xu J. Clinically available RNA profiling tests of prostate tumors: utility and comparison. Asian J Androl. 2016;18(4):575-9.

8. Seven M, Karatas OF, Duz MB, Ozen M. The role of miRNAs in cancer: from pathogenesis to therapeutic implications. Future Oncol. 2014;10(6):1027-48.

9. Iorio MV, Croce CM. MicroRNAs in cancer: small molecules with a huge impact. J Clin Oncol. 2009;27(34):5848-56.

10. van Rooij E, Olson EN. MicroRNA therapeutics for cardiovascular disease: opportunities and obstacles. Nat Rev Drug Discov. 2012;11(11):860-72.

11. Iorio MV, Croce CM. MicroRNA dysregulation in cancer: diagnostics, monitoring and therapeutics. A comprehensive review. EMBO Mol Med. 2012;4(3):143-59.

12. Lu J, Getz G, Miska EA, Alvarez-Saavedra E, Lamb J, Peck D, Sweet-Cordero A, Ebert BL, Mak RH, Ferrando AA, et al. MicroRNA expression profiles classify human cancers. Nature. 2005;435(7043):834-8.

13. Spahn M, Kneitz S, Scholz CJ, Stenger N, Rudiger T, Strobel P, Riedmiller H, Kneitz B. Expression of microRNA-221 is progressively reduced in aggressive prostate cancer and metastasis and predicts clinical recurrence. Int J Cancer. 2010;127(2):394-403.

14. Jansen FH, Roobol M, Jenster G, Schroder FH, Bangma CH. Screening for prostate cancer in $2008 \mathrm{Il}$ : the importance of molecular subforms of prostate-specific antigen and tissue kallikreins. Eur Urol. 2009;55(3):563-74.

15. Miyake H, Fujisawa M. Prognostic prediction following radical prostatectomy for prostate cancer using conventional as well as molecular biological approaches. Int J Urol. 2013;20(3):301-11.

16. Moch H, Cubilla AL, Humphrey PA, Reuter VE, Ulbright TM. The 2016 WHO classification of Tumours of the urinary system and male genital organs-part a: renal, penile, and testicular Tumours. Eur Urol. 2016;70(1):93-105.

17. Lu Y, Baras AS, Halushka MK. miRge 2.0 for comprehensive analysis of microRNA sequencing data. BMC Bioinformatics. 2018;19(1):275.

18. Griffiths-Jones S, Grocock RJ, van Dongen S, Bateman A, Enright AJ. miRBase: microRNA sequences, targets and gene nomenclature. Nucleic Acids Res. 2006;34(Database issue):D140-4.

19. Robinson MD, McCarthy DJ, Smyth GK. edgeR: a bioconductor package for differential expression analysis of digital gene expression data. Bioinformatics. 2010;26(1):139-40.

20. Vlachos IS, Zagganas K, Paraskevopoulou MD, Georgakilas G, Karagkouni D, Vergoulis T, Dalamagas T, Hatzigeorgiou AG. DIANA-miRPath v3.0: deciphering microRNA function with experimental support. Nucleic Acids Res. 2015;43(W1):W460-6.

21. Karagkouni D, Paraskevopoulou MD, Chatzopoulos S, Vlachos IS, Tastsoglou S, Kanellos I, Papadimitriou D, Kavakiotis I, Maniou S, Skoufos G, et al. DIANA-TarBase v8: a decade-long collection of experimentally supported miRNA-gene interactions. Nucleic Acids Res. 2018;46(D1):D239-45.

22. Luo W, Pant G, Bhavnasi YK, Blanchard SG Jr, Brouwer C. Pathview web: user friendly pathway visualization and data integration. Nucleic Acids Res. 2017; 45(W1):W501-8

23. Szklarczyk D, Morris JH, Cook H, Kuhn M, Wyder S, Simonovic M, Santos A, Doncheva NT, Roth A, Bork P, et al. The STRING database in 2017: qualitycontrolled protein-protein association networks, made broadly accessible. Nucleic Acids Res. 2017;45(D1):D362-8.
24. Ren LH, Chen WX, Li S, He XY, Zhang ZM, Li M, Cao RS, Hao B, Zhang HJ, Qiu HQ, et al. MicroRNA-183 promotes proliferation and invasion in oesophageal squamous cell carcinoma by targeting programmed cell death 4. Br J Cancer. 2014;111(10):2003-13.

25. Qiu M, Liu L, Chen L, Tan G, Liang Z, Wang K, Liu J, Chen H. microRNA-183 plays as oncogenes by increasing cell proliferation, migration and invasion via targeting protein phosphatase $2 \mathrm{~A}$ in renal cancer cells. Biochem Biophys Res Commun. 2014;452(1):163-9.

26. Sarver AL, Li L, Subramanian S. MicroRNA miR-183 functions as an oncogene by targeting the transcription factor EGR1 and promoting tumor cell migration. Cancer Res. 2010;70(23):9570-80.

27. Lin H, Dai T, Xiong H, Zhao X, Chen X, Yu C, Li J, Wang X, Song L. Unregulated miR-96 induces cell proliferation in human breast cancer by downregulating transcriptional factor FOXO3a. PLOS One. 2010;5(12):e15797.

28. Myatt SS, Wang J, Monteiro LJ, Christian M, Ho KK, Fusi L, Dina RE, Brosens JJ, Ghaem-Maghami S, Lam EW. Definition of microRNAs that repress expression of the tumor suppressor gene FOXO1 in endometrial cancer Cancer Res. 2010;70(1):367-77.

29. Larne O, Martens-Uzunova E, Hagman Z, Edsjo A, Lippolis G, den Berg MS, Bjartell A, Jenster G, Ceder Y. miQ--a novel microRNA based diagnostic and prognostic tool for prostate cancer. Int J Cancer. 2013;132(12):2867-75.

30. Siu MK, Tsai YC, Chang YS, Yin JJ, Suau F, Chen WY, Liu YN. Transforming growth factor-beta promotes prostate bone metastasis through induction of microRNA-96 and activation of the mTOR pathway. Oncogene. 2015; 34(36):4767-76.

31. Ma Y, Liang AJ, Fan YP, Huang YR, Zhao XM, Sun Y, Chen XF. Dysregulation and functional roles of miR-183-96-182 cluster in cancer cell proliferation, invasion and metastasis. Oncotarget. 2016;7(27):42805-25.

32. Schaefer A, Jung M, Mollenkopf HJ, Wagner I, Stephan C, Jentzmik F, Miller K, Lein M, Kristiansen G, Jung K. Diagnostic and prognostic implications of microRNA profiling in prostate carcinoma. Int J Cancer. 2010;126(5):1166-76.

33. Casanova-Salas I, Rubio-Briones J, Calatrava A, Mancarella C, Masia E, Casanova J, Fernandez-Serra A, Rubio L, Ramirez-Backhaus M, Arminan A, et al. Identification of miR-187 and miR-182 as biomarkers of early diagnosis and prognosis in patients with prostate cancer treated with radical prostatectomy. J Urol. 2014;192(1):252-9.

34. Wang D, Lu G, Shao Y, Xu D. MiR-182 promotes prostate cancer progression through activating Wnt/beta-catenin signal pathway. Biomed Pharmacother. 2018;99:334-9.

35. Petrocca F, Vecchione A, Croce CM. Emerging role of miR-106b-25/miR-1792 clusters in the control of transforming growth factor beta signaling. Cancer Res. 2008;68(20):8191-4.

36. Zhao H, Wang Y, Yang L, Jiang R, Li W. MiR-25 promotes gastric cancer cells growth and motility by targeting RECK. Mol Cell Biochem. 2014;385(1-2): 207-13.

37. Hudson RS, Yi M, Esposito D, Glynn SA, Starks AM, Yang Y, Schetter AJ, Watkins SK, Hurwitz AA, Dorsey TH, et al. MicroRNA-106b-25 cluster expression is associated with early disease recurrence and targets caspase-7 and focal adhesion in human prostate cancer. Oncogene. 2013;32(35):413947.

38. Martens-Uzunova ES, Jalava SE, Dits NF, van Leenders GJ, Moller S, Trapman J, Bangma CH, Litman T, Visakorpi T, Jenster G. Diagnostic and prognostic signatures from the small non-coding RNA transcriptome in prostate cancer. Oncogene. 2012;31(8):978-91.

39. Liu MX, Liao J, Xie M, Gao ZK, Wang XH, Zhang Y, Shang MH, Yin LH, Pu YP, Liu R. miR-93-5p transferred by Exosomes promotes the proliferation of esophageal Cancer cells via intercellular communication by targeting PTEN. Biomed Environ Sci. 2018:31(3):171-85.

40. Yang W, Bai J, Liu D, Wang S, Zhao N, Che R, Zhang H. MiR-93-5p upregulation is involved in non-small cell lung cancer cells proliferation and migration and poor prognosis. Gene. 2018;647:13-20.

41. Choi N, Park J, Lee JS, Yoe J, Park GY, Kim E, Jeon H, Cho YM, Roh TY, Lee Y. miR-93/miR-106b/miR-375-CIC-CRABP1: a novel regulatory axis in prostate cancer progression. Oncotarget. 2015;6(27):23533-47.

42. Foekens JA, Sieuwerts AM, Smid M, Look MP, de Weerd V, Boersma AW, Klijn JG, Wiemer EA, Martens JW. Four miRNAs associated with aggressiveness of lymph node-negative, estrogen receptor-positive human breast cancer. Proc Natl Acad Sci U S A. 2008;105(35):13021-6.

43. Fang $Y$, Xue JL, Shen Q, Chen J, Tian L. MicroRNA-7 inhibits tumor growth and metastasis by targeting the phosphoinositide 3-kinase/Akt pathway in hepatocellular carcinoma. Hepatology. 2012;55(6):1852-62. 
44. Chang YL, Zhou PJ, Wei L, Li W, Ji Z, Fang YX, Gao WQ. MicroRNA-7 inhibits the stemness of prostate cancer stem-like cells and tumorigenesis by repressing KLF4/PI3K/Akt/p21 pathway. Oncotarget. 2015;6(27):24017-31.

45. Mukai $R$, Tomimaru $Y$, Nagano $H$, Eguchi $H$, Mimori K, Tomokuni A, Asaoka T, Wada H, Kawamoto K. Marubashi S et al: miR-615-3p expression level in bone marrow is associated with tumor recurrence in hepatocellular carcinoma. Mol Clin Oncol. 2015;3(3):487-94.

46. Wang J, Liu L, Sun Y, Xue Y, Qu J, Pan S, Li H, Qu H, Wang J, Zhang J. miR615-3p promotes proliferation and migration and inhibits apoptosis through its potential target CELF2 in gastric cancer. Biomed Pharmacother. 2018;101:406-13.

47. Laursen EB, Fredsoe J, Schmidt L, Strand SH, Kristensen H, Rasmussen AKI, Daugaard TF, Mouritzen P, Hoyer S, Kristensen G, et al. Elevated miR-615-3p expression predicts adverse clinical outcome and promotes proliferation and migration of prostate Cancer cells. Am J Pathol. 2019;189(12):2377-88.

48. Bai M, Zhang H, Si L, Yu N, Zeng A, Zhao R. Upregulation of serum miR-10b is associated with poor prognosis in patients with melanoma. J Cancer. 2017;8(13):2487-91.

49. Heidary MF, Mahmoodzadeh Hosseini $H$, Mehdizadeh Aghdam E, Nourani MR, Ranjbar R, Mirnejad R, Imani Fooladi AA. Overexpression of metastatic related MicroRNAs, Mir-335 and Mir-10b, by staphylococcal enterotoxin B in the metastatic breast Cancer cell line. Adv Pharm Bull. 2015;5(2):255-9.

50. Zhang Y, Han T, Feng D, Li J, Wu M, Peng X, Wang B, Zhan X, Fu P. Screening of non-invasive miRNA biomarker candidates for metastasis of gastric cancer by small RNA sequencing of plasma exosomes. Carcinogenesis. 2019.

51. Du HY, Liu B. MiR-1271 as a tumor suppressor in breast cancer proliferation and progression via targeting SPIN1. Eur Rev Med Pharmacol Sci. 2018;22(9): 2697-706.

52. Maurel M, Jalvy S, Ladeiro Y, Combe C, Vachet L, Sagliocco F, Bioulac-Sage P, Pitard $V$, Jacquemin-Sablon $H$, Zucman-Rossi J, et al. A functional screening identifies five microRNAs controlling glypican-3: role of miR-1271 downregulation in hepatocellular carcinoma. Hepatology. 2013;57(1):195-204.

53. Sun $X$, Zhai $H$, Chen $X$, Kong R, Zhang X. MicroRNA-1271 suppresses the proliferation and invasion of colorectal cancer cells by regulating metadherin/Wnt signaling. J Biochem Mol Toxicol. 2018;32(2).

54. Jiao Y, Zhu G, Yu J, Li Y, Wu M, Zhao J, Tian X. miR-1271 inhibits growth, invasion and epithelial-mesenchymal transition by targeting ZEB1 in ovarian cancer cells. Onco Targets Ther. 2019;12:6973-80.

55. Su Z, Chen D, Li Y, Zhang E, Yu Z, Chen T, Jiang Z, Ni L, Yang S, Gui Y, et al. microRNA-184 functions as tumor suppressor in renal cell carcinoma. Exp Ther Med. 2015;9(3):961-6.

56. Zhen $Y$, Liu Z, Yang H, Yu X, Wu Q, Hua S, Long X, Jiang $Q$, Song $Y$, Cheng $C$, et al. Tumor suppressor PDCD4 modulates miR-184-mediated direct suppression of C-MYC and BCL2 blocking cell growth and survival in nasopharyngeal carcinoma. Cell Death Dis. 2013;4:e872.

57. Tivnan A, Foley NH, Tracey L, Davidoff AM, Stallings RL. MicroRNA-184mediated inhibition of tumour growth in an orthotopic murine model of neuroblastoma. Anticancer Res. 2010;30(11):4391-5.

58. Lin TC, Lin PL, Cheng YW, Wu TC, Chou MC, Chen CY, Lee H. MicroRNA-184 deregulated by the MicroRNA-21 promotes tumor malignancy and poor outcomes in non-small cell lung Cancer via targeting CDC25A and c-Myc. Ann Surg Oncol. 2015;22(Suppl 3):S1532-9.

59. Feng R, Dong L. Inhibitory effect of miR-184 on the potential of proliferation and invasion in human glioma and breast cancer cells in vitro. Int J Clin Exp Pathol. 2015;8(8):9376-82.

60. Galardi S, Mercatelli N, Giorda E, Massalini S, Frajese GV, Ciafre SA, Farace MG. miR-221 and miR-222 expression affects the proliferation potential of human prostate carcinoma cell lines by targeting p27Kip1. J Biol Chem. 2007;282(32):23716-24

61. Song Z, Li G. Role of specific microRNAs in regulation of vascular smooth muscle cell differentiation and the response to injury. J Cardiovasc Transl Res. 2010;3(3):246-50.

62. Chistiakov DA, Sobenin IA, Orekhov AN, Bobryshev YV. Human miR-221/222 in physiological and atherosclerotic vascular remodeling. Biomed Res Int. 2015;2015:354517.

63. Sun $T$, Yang M, Chen S, Balk S, Pomerantz M, Hsieh CL, Brown M, Lee GM, Kantoff PW. The altered expression of MiR-221/-222 and MiR-23b/-27b is associated with the development of human castration resistant prostate cancer. Prostate. 2012;72(10):1093-103.
64. Goto Y, Kojima S, Nishikawa R, Kurozumi A, Kato M, Enokida H, Matsushita R, Yamazaki K, Ishida Y, Nakagawa M, et al. MicroRNA expression signature of castration-resistant prostate cancer: the microRNA-221/222 cluster functions as a tumour suppressor and disease progression marker. Br J Cancer. 2015; 113(7):1055-65

65. Coarfa C, Fiskus W, Eedunuri VK, Rajapakshe K, Foley C, Chew SA, Shah SS, Geng C, Shou J, Mohamed JS, et al. Comprehensive proteomic profiling identifies the androgen receptor axis and other signaling pathways as targets of microRNAs suppressed in metastatic prostate cancer. Oncogene. 2016:35(18):2345-56.

66. Kiener M, Chen L, Krebs M, Grosjean J, Klima I, Kalogirou C, Riedmiller H, Kneitz B, Thalmann GN, Snaar-Jagalska E, et al. miR-221-5p regulates proliferation and migration in human prostate cancer cells and reduces tumor growth in vivo. BMC Cancer. 2019;19(1):627.

67. Alshalalfa M. MicroRNA response elements-mediated miRNA-miRNA interactions in prostate Cancer. Adv Bioinforma. 2012;2012:839837.

68. Segura MF, Belitskaya-Levy I, Rose AE, Zakrzewski J, Gaziel A, Hanniford D, Darvishian F, Berman RS, Shapiro RL, Pavlick AC, et al. Melanoma MicroRNA signature predicts post-recurrence survival. Clin Cancer Res. 2010;16(5):1577-86.

69. Swierniak M, Wojcicka A, Czetwertynska M, Stachlewska E, Maciag M, Wiechno W, Gornicka B, Bogdanska M, Koperski L, de la Chapelle A, et al. In-depth characterization of the microRNA transcriptome in normal thyroid and papillary thyroid carcinoma. J Clin Endocrinol Metab. 2013;98(8):E1401-9.

70. Zhao Y, Yan M, Yun Y, Zhang J, Zhang R, Li Y, Wu X, Liu Q, Miao W, Jiang H. MicroRNA-455-3p functions as a tumor suppressor by targeting elF4E in prostate cancer. Oncol Rep. 2017;37(4):2449-58.

71. Wu XL, Cheng B, Li PY, Huang HJ, Zhao Q, Dan ZL, Tian DA, Zhang P. MicroRNA-143 suppresses gastric cancer cell growth and induces apoptosis by targeting COX-2. World J Gastroenterol. 2013;19(43):7758-65.

72. He M, Zhan M, Chen W, Xu S, Long M, Shen H, Shi Y, Liu Q, Mohan M, Wang J. MiR-143-5p deficiency triggers EMT and metastasis by targeting HIF-1alpha in gallbladder Cancer. Cell Physiol Biochem. 2017;42(5):2078-92.

73. Jin X, Chen X, Hu Y, Ying F, Zou R, Lin F, Shi Z, Zhu X, Yan X, Li S, et al. LncRNA-TCONS_00026907 is involved in the progression and prognosis of cervical cancer through inhibiting miR-143-5p. Cancer Med. 2017;6(6):1409-23.

74. Zabaglia LM, Bartolomeu NC, Dos Santos MP, Peruquetti RL, Chen E, de Arruda Cardoso Smith M, SLM P, Rasmussen LT. Decreased MicroRNA miR181c expression associated with gastric Cancer. J Gastrointest Cancer. 2018; 49(1):97-101.

75. Yamazaki N, Koga Y, Taniguchi H, Kojima M, Kanemitsu Y, Saito N, Matsumura Y. High expression of miR-181c as a predictive marker of recurrence in stage II colorectal cancer. Oncotarget. 2017;8(4):6970-83.

76. Zhang WL, Zhang JH. miR-181c promotes proliferation via suppressing PTEN expression in inflammatory breast cancer. Int J Oncol. 2015;46(5):2011-20.

77. Fu Y, Tang Y, Wang J, Guo Z. MicroRNA-181c suppresses the biological progression of osteosarcoma via targeting SMAD7 and regulating transforming growth factor-beta (TGF-beta) signaling pathway. Med Sci Monit. 2019;25:4801-10.

78. Ai J, Gong C, Wu J, Gao J, Liu W, Liao W, Wu L. MicroRNA181c suppresses growth and metastasis of hepatocellular carcinoma by modulating NCAPG. Cancer Manag Res. 2019;11:3455-67.

79. Chai J, Wang S, Han D, Dong W, Xie C, Guo H. MicroRNA-455 inhibits proliferation and invasion of colorectal cancer by targeting RAF proto-oncogene serine/threonine-protein kinase. Tumour Biol. 2015; 36(2):1313-21.

80. Liu J, Zhang J, Li Y, Wang L, Sui B, Dai D. MiR-455-5p acts as a novel tumor suppressor in gastric cancer by down-regulating RAB18. Gene. 2016;592(2):308-15.

81. Qin L, Zhang Y, Lin J, Shentu Y, Xie X. MicroRNA-455 regulates migration and invasion of human hepatocellular carcinoma by targeting Runx2. Oncol Rep. 2016;36(6):3325-32.

82. Xing $\mathrm{Q}$, Xie H, Zhu B, Sun Z, Huang Y. MiR-455-5p suppresses the progression of prostate Cancer by targeting CCR5. Biomed Res Int. 2019; 2019:6394784.

83. Koh CM, Bieberich CJ, Dang CV, Nelson WG, Yegnasubramanian S, De Marzo AM. MYC and prostate Cancer. Genes Cancer. 2010;1(6):617-28.

84. Hawksworth D, Ravindranath L, Chen Y, Furusato B, Sesterhenn IA, McLeod DG, Srivastava S, Petrovics G. Overexpression of C-MYC oncogene in prostate cancer predicts biochemical recurrence. Prostate Cancer Prostatic Dis. 2010;13(4):311-5.

85. Huang T, Sun L, Yuan X, Qiu H. Thrombospondin-1 is a multifaceted player in tumor progression. Oncotarget. 2017;8(48):84546-58. 
86. Shangary S, Wang S. Targeting the MDM2-p53 interaction for cancer therapy. Clin Cancer Res. 2008;14(17):5318-24.

87. Tovar C, Higgins B, Kolinsky K, Xia M, Packman K, Heimbrook DC, Vassilev LT. MDM2 antagonists boost antitumor effect of androgen withdrawal: implications for therapy of prostate cancer. Mol Cancer. 2011;10:49.

88. Feng FY, Zhang Y, Kothari V, Evans JR, Jackson WC, Chen W, Johnson SB, Luczak C, Wang S, Hamstra DA. MDM2 inhibition sensitizes prostate Cancer cells to androgen ablation and radiotherapy in a p53-dependent manner. Neoplasia. 2016;18(4):213-22.

89. Valencia T, Joseph A, Kachroo N, Darby S, Meakin S, Gnanapragasam VJ. Role and expression of FRS2 and FRS3 in prostate cancer. BMC Cancer. 2011;11:484

90. Chen Y, McGee J, Chen X, Doman TN, Gong X, Zhang Y, Hamm N, Ma X, Higgs RE, Bhagwat SV, et al. Identification of druggable cancer driver genes amplified across TCGA datasets. PLoS One. 2014:9(5):e98293.

91. Su W, Hong L, Xu X, Huang S, Herpai D, Li L, Xu Y, Truong L, Hu WY, Wu X, et al. miR-30 disrupts senescence and promotes cancer by targeting both p16(INK4A) and DNA damage pathways. Oncogene. 2018;37(42):5618-32.

92. Bhardwaj A, Singh S, Srivastava SK, Arora S, Hyde SJ, Andrews J, Grizzle WE, Singh AP. Restoration of PPP2CA expression reverses epithelial-tomesenchymal transition and suppresses prostate tumour growth and metastasis in an orthotopic mouse model. Br J Cancer. 2014:110(8):2000-10.

93. Tsui KH, Chiang KC, Lin YH, Chang KS, Feng TH, Juang HH. BTG2 is a tumor suppressor gene upregulated by p53 and PTEN in human bladder carcinoma cells. Cancer Med. 2018;7(1):184-95.

94. Ro SH, Xue X, Ramakrishnan SK, Cho CS, Namkoong S, Jang I, Semple IA, Ho A, Park HW, Shah YM, et al. Tumor suppressive role of sestrin2 during colitis and colon carcinogenesis. Elife. 2016;5:e12204.

\section{Publisher's Note}

Springer Nature remains neutral with regard to jurisdictional claims in published maps and institutional affiliations.

Ready to submit your research? Choose BMC and benefit from:

- fast, convenient online submission

- thorough peer review by experienced researchers in your field

- rapid publication on acceptance

- support for research data, including large and complex data types

- gold Open Access which fosters wider collaboration and increased citations

- maximum visibility for your research: over $100 \mathrm{M}$ website views per year

At $\mathrm{BMC}$, research is always in progress.

Learn more biomedcentral.com/submissions 